Plástica 


\title{
La ausencia: entre Sillas y Perreras la realidad de un país
}

\author{
Elizabeth Marín Hernández
}

Doctora en Historia del Arte por la Universidad de Barcelona, España. Profesora del Departamento de Historia del Arte de la Universidad de Los Andes, Mérida-Venezuela de las cátedras de Arte Latinoamericano y Arte Contemporáneo. Investigadora activa de la Universidad de Los Andes, Mérida-Venezuela. Ha realizado múltiples publicaciones

en revistas nacionales e internacionales sobre arte contemporáneo. Coordinadora y curadora de Espacio Proyecto Libertad, iniciativa para la exhibición y discusión del arte contemporáneo venezolano en la ciudad de Mérida-Venezuela.

La Venezuela actual exhibe un rostro desfigurado, extraño, de difícil comprensión, como consecuencia de la división de una sociedad que ha sido manipulada por medio de reciclados discursos revolucionarios, que aún no han perdido su anclaje en el pensamiento de muchos, sin comprender el cambio de los tiempos y las afectaciones que los mismos pueden ocasionar.

Revolución, decretada, no ge-

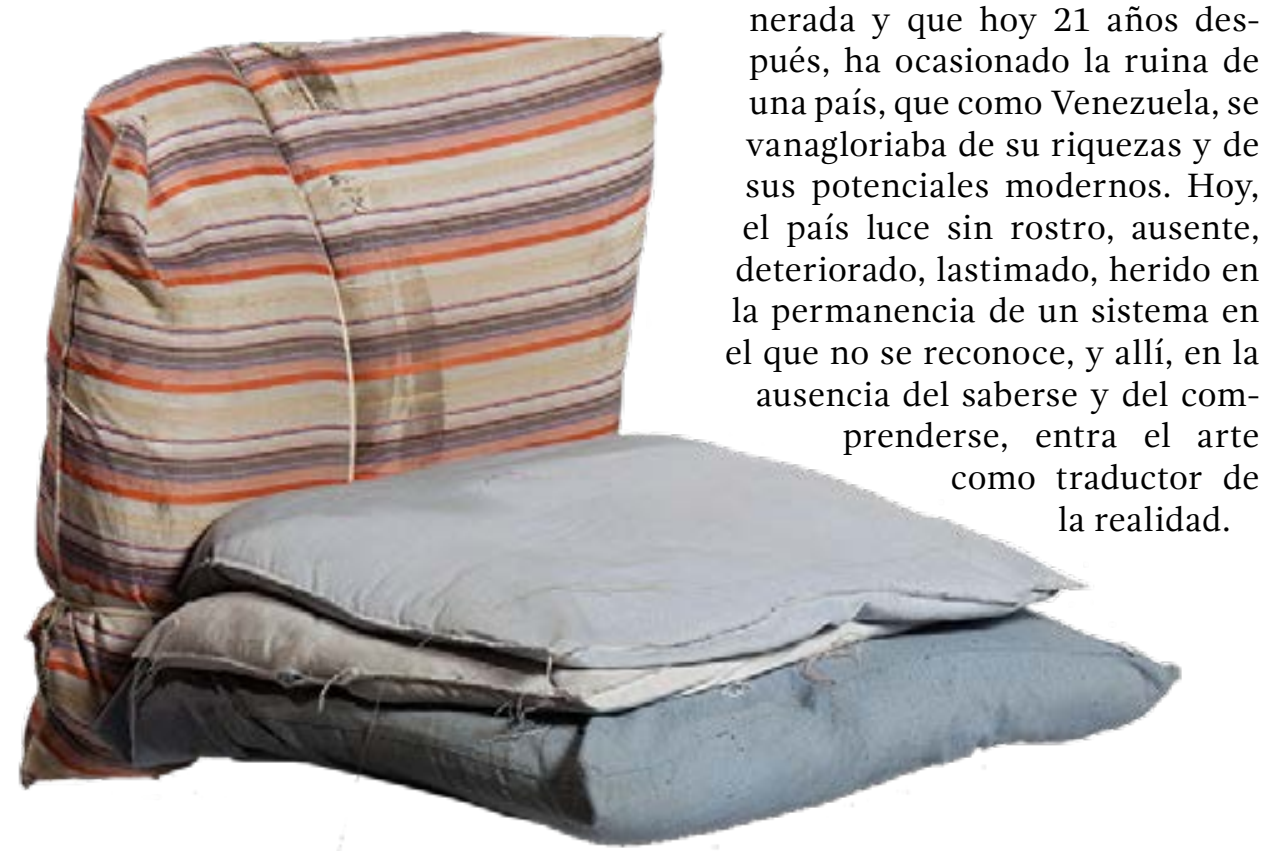




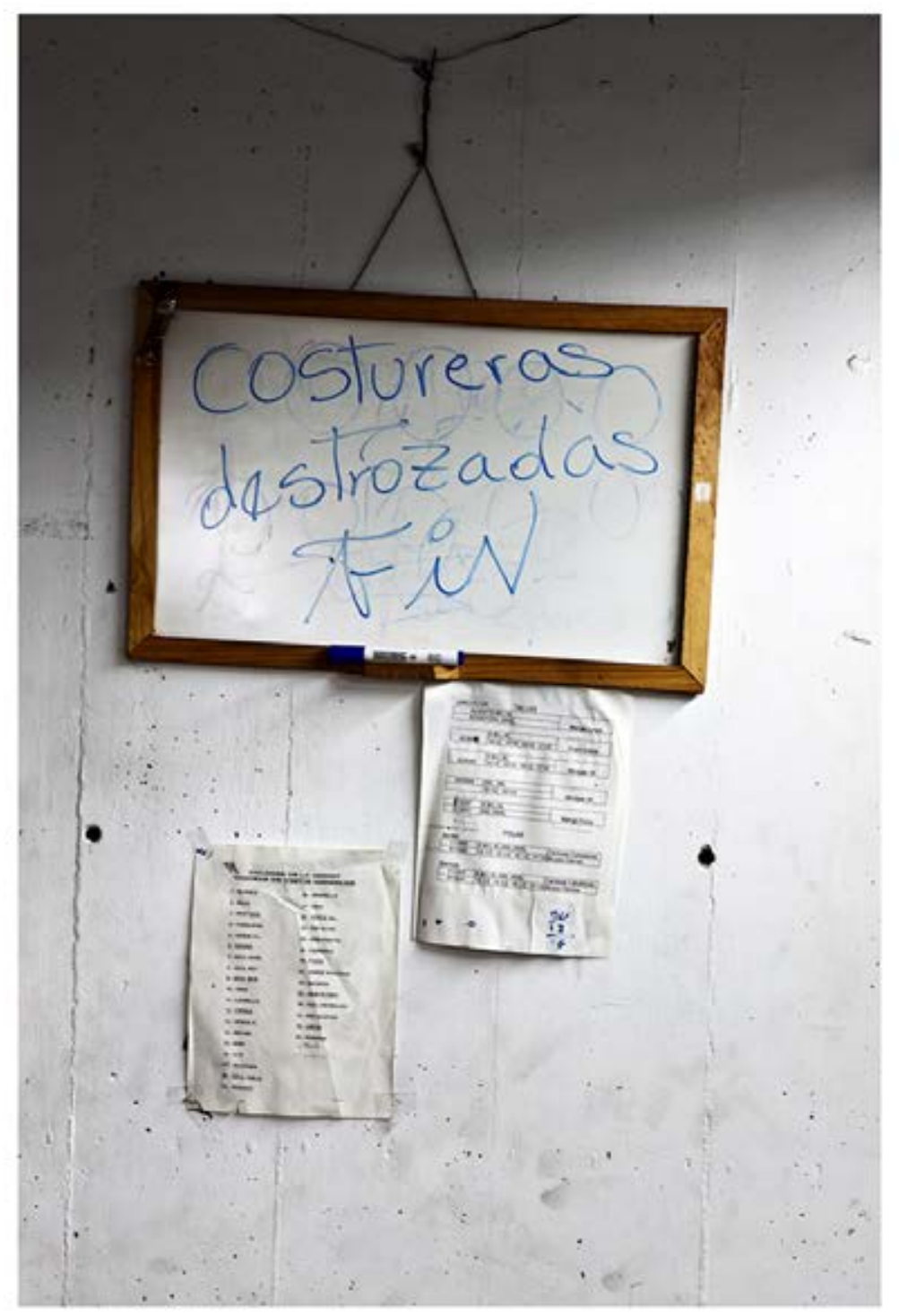

$\stackrel{2}{2}$

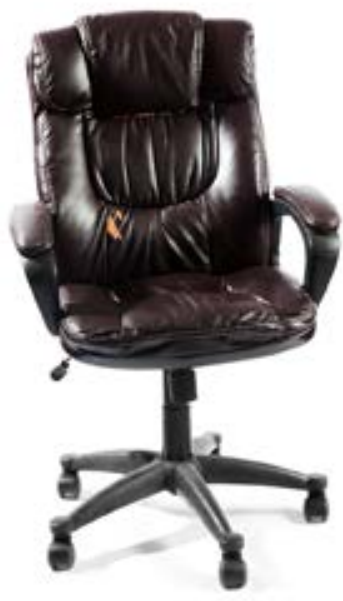

134 Universidades | núm. 83, enero-marzo 2020 | UDUAL

Elizabeth Marín Hernández | La ausencia: entre Sillas y Perreras la realidad de un país 
Una realidad que es alegorizada en la viudez de las Sillas (2016), de Juan Toro-Diez (Caracas, 1969) que manifiestan los puestos perdidos de trabajo de una textilera ante el agobio económico ocasionado por el régimen a la producción nacional. Cierre de fábricas, despido de personal, ausencia de garantías para la producción, expropiaciones.

Todo colapsa en medio de una fantasiosa lucha con los otros: el imperio, el colonizador, el terrateniente, el conocimiento, el pueblo en armas, y mientras el tiempo pasa en el aceleramiento de las redes y el detenimiento del país por un discurso libertario, el venezolano de a pie se ha convertido en el padeciente del caos.
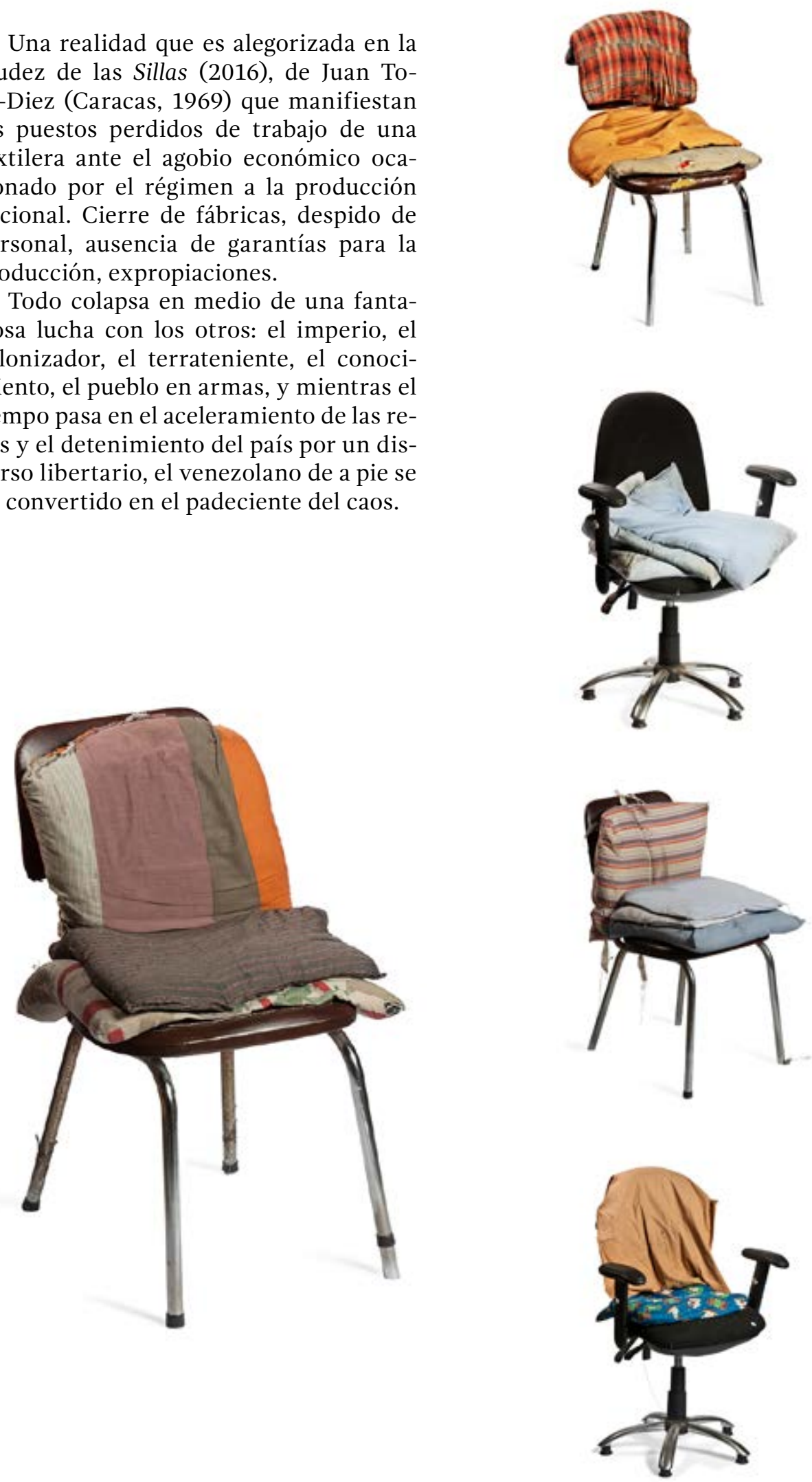
Aquellos, que alguna vez empleados, hoy sobreviven en las calles del país en medio de la precariedad, la ausencia de servicios públicos, de transporte, de combustible. Emergencia, sobrevivencia de la movilización, "las perreras". Sistema de transporte inseguro, frágil, en el que cada día miles de venezolanos se desplazan por medio de extraños y complejos recorridos con la intención de arribar a sus destinos. Cualquier camión sirve, mientras puedan subirse a una plataforma que los transporte, sin pensar en los riesgos que esto ocasiona, la tensión emocional a la que están sometidos.

Esa situación es tomada como materia simbólica y representacional por la joven artista Génesis Alayón (Villa de Cura, 1995), quien pacientemente recorre la ciudad captando a esos transportes, a las personas que los habitan, pero en Patrones de recorrido (2019), solo hay ausencia, tensión de la fragilidad y de trayectorias sobrepuestas a la dificultad.

Venezuela desaparece, se deslava, en la ausencia de la civilidad, de lo que fuimos, pero que aún lucha por lo que desea ser.

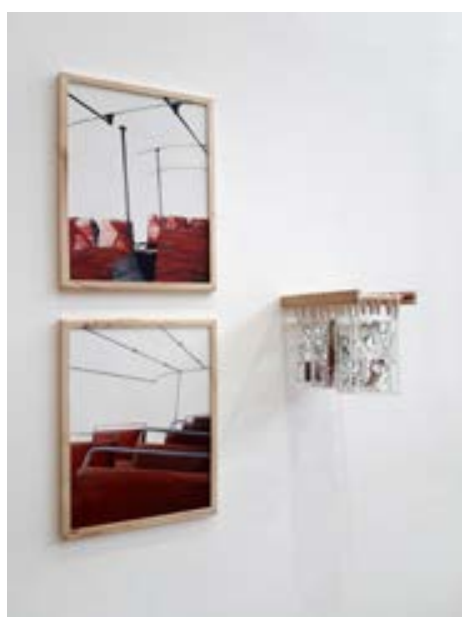

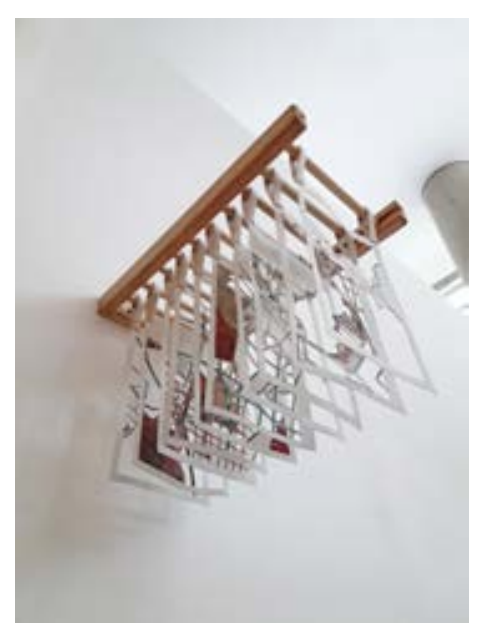
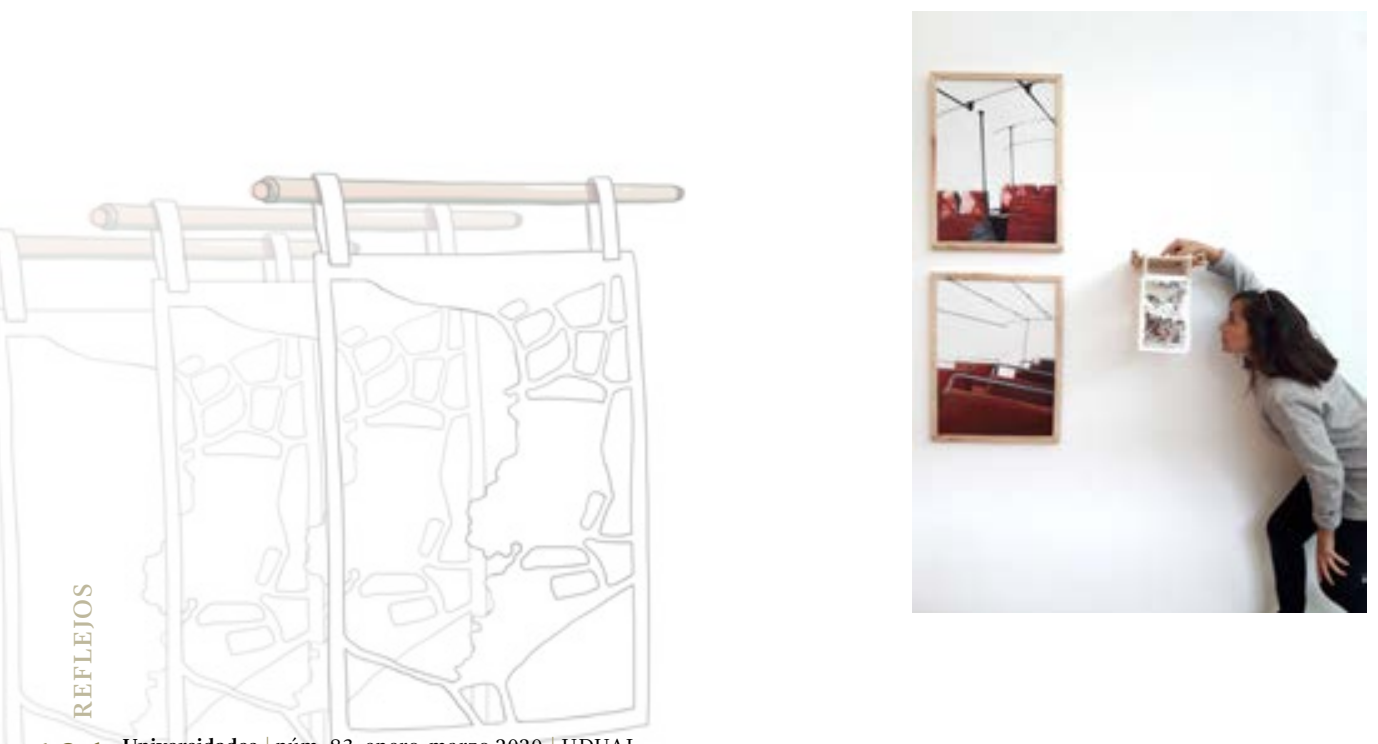

136 Universidades $\mid$ núm. 83, enero-marzo $2020 \mid$ UDUAL 